\title{
Painel de Indicadores de Condicionalidades ${ }^{1}$
}

\section{Introducão}

O presente trabalho é um relato da criação e manutenção do painel de indicadores de condicionalidades do programa bolsa família, desenvolvido Pela Coordenação Geral de Apoio à Integração de Ações do Departamento de Condicionalidades da Secretaria Nacional de Renda de Cidadania.

1 Parte dos textos, tabelas, figuras e gráficos utilizados no trabalho foi produzida pelos autores na condição de interno do MDS (relatórios, apresentações de âmbito interno etc.) e adaptada para integrar o texto. Porém esses documentos permanecem não publicados, sendo usados apenas para seus fins iniciais. No caso de materiais publicados, mesmo que para circulação interna, será feita a devida citação.

2 Coordenador Geral de Apoio à Integração de Ações DECON/SENARC/MDS

3 Consultora UNESCO atuando na Coordenação Geral de integração de Ações DECON/

SENARC/MDS

4 Coordenador Geral de Acompanhamento de Condicionalidades DECON/ SENARC/MDS

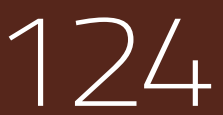

O Programa Bolsa Família PBF) econstitui na transferência de renda direta, voltado às famílias em situação de pobreza e extrema pobreza. busca proporcionar a saída imediata do nível de indigência, possibilitando, por meio do cumprimento das condicionalidades, o acesso aos direitos básicos nas áreas da Saúde, da Educação e da Assistência Social, constituindo, assim, o compromisso tanto por parte das famílias,opelo exercício de seus direitos, quanto do poder público que assume a responsabilidade da oferta de serviços.

As condicionalidades são as seguintes: na área de educação, as crianças e adolescentes de 6 a 15 anos tem que apresentar uma frequência escolar superior a $85 \%$ e os jovens de 16 e 17 anos, de 75\%. Na área de saúde, são requisitados o acompanhamento do calendário vacinal, do crescimento e desenvolvimento (avaliação nutricional) de crianças de 0 a 7 anos, pré-natal para gestantes e acompanhamento de nutrizes.

A gestão das condicionalidades é realizada de forma conjunta pelos Ministérios do Desenvolvimento Social e Combate à Fome (MDS), da Saúde e da Educação, que são responsáveis pela definição de diretrizessdessa gestão junto aos estados e municípios. Os objetivos da gestão compartilhada são monitorar o cumprimento dos compromissos pelas famílias beneficiárias, de acordo com a legislação do Programa; responsabilizar o poder público pela garantia de acesso aos serviços e pela identificação das famílias mais excluídas e vulneráveis; e identificar, nos casos de não cumpri- 
mento, as famílias em situação de maior vulnerabilidade e orientar ações do poder público para o devido acompanhaments 5 .

Nos casos das famílias que não cumprem as condicionalidades, de acordo com a Portaria GM/MDS no 251 de 12 de dezembro de 2012, serão realizadas ações de efeitos gradativos que vão desde a advertência da família, passando pela suspensão do benefício, podendo chegar ao cancelamento. Permite ainda que as famíliassem falta com as condições sejam identificadas e acompanhadas, a fim de que os problemas que geraram o descumprimento possam ser resolvidos.

O monitoramento das informações de condicionalidades é uma necessidade para o bom funcionamento do programa bolsa família, não apenas como forma de melhorar a gestão e a oferta de serviços aos beneficiários, como também observar o aparecimento de vulnerabilidades e problemas potenciais. Por isso, como instrumento de monitoramento, o painel tem duas funções: uma de gestão das condicionalidades no nível federativo, com foco nas administrações estaduais e municipais do PBF, e uma no nível do beneficiário, observando os padrões de oferta e atendimento da condicionalidade, antecipando, assim, problemas de oferta de serviços e cumprimento das condicionalidades.
Embora o Painel de indicadores de condicionalidades esteja em uma fase conceitualmente avançada, em termos de plataforma ainda é apresentado intencionalmente de forma simplee. Isso se dá pelos múltiplos usos das informações existentes e pela necessidade de flexibilidade na extração da informação. Por esse motivo, o painel permanece basicamente como uma planilha de Excel, embora alimente outros sistemas automatizados, especialmente aplicações de monitoramento desenvolvidas pela Secretaria de Avaliação e Gestão da Informação (SAGI) do MDS.

O trabalho deter-se-á mais em uma ótica conceitual e nos usos das informações, e menos nos aspectos técnicos da construção dos indicadores. Eventualmente, a construção de alguns indicadores mais importanteseserá mostrada com maior detalhs, para uma melhor compreensão do trabalho desenvolvido.

O trabalho está dividido em cinco seções: após esta seção introdutória, a segunda trata do processo de acompanhamento das condicionalidades e da divisão conceitual do painel; a terceiraoversa sobre o processo de divisão territorial e séries temporais existentes, a quarta seção faz uma breve análise dos indicadores e da sua tipologia, e a última parte trata dos usos na gestão e os produtos derivados das informações existentes. 


\section{Os sistemas de} informação envolvidos nas condicionalidadese

O acompanhamento das condicionalidades é extremamente complexa, por alguns aspectos. Em primeiro lugar, o levantamento dessas informações se dá em um contexto federativo complexo ${ }^{6}$, onde as informações são enviadas aos ministérios parceiros e posteriormente aos municípios para coleta, por meio de sistemas próprios. Este mesmo caminho é feito no sentido contrário. Em segundr, o trabalho é intersetorial ${ }^{7}$, com o complicador técnics, no nível de integração de sistemas.
Por isso, inicialmente devemos estabelecer como estão localizados os sistemas de informação que tornam possível esse controle, e como se dá a troca de informações entreseles.

Além disso, a operação em si é extremamente complexa: para se ter uma ideia, são acompanhados, bimestralmente, cerca de 16 milhões de alunos e, semestralmente, mais de 8 milhões de famílias na saúde, distribuídos nos 5.570 municípios nas 27 unidades da federação. Mais de $160 \mathrm{mil}$ escolas no paísmconta com estudantes $\mathrm{PBF}$, sendo que mais de 70 mil delas tem a maioria de seus estudantes no programa.

\section{- FIGURA 1: FERRAMENTAS DE INFORMAÇÃO DAS CONDICIONALIDADES DO PROGRAMA BOLA FAMÍLIA}

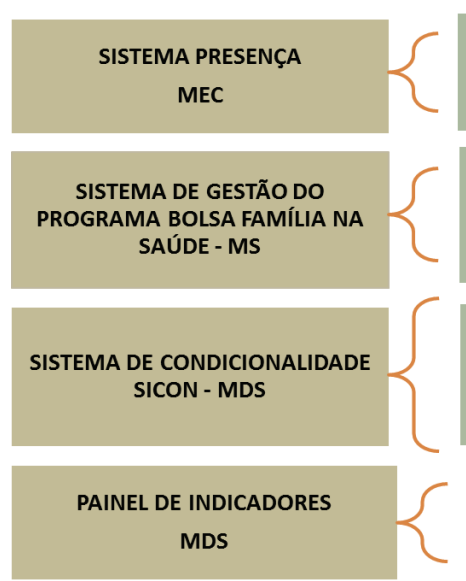

- Registro nominal da frequência escolar

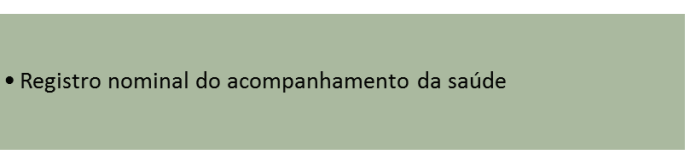

- Ferramenta que subsidia a gestão intersetorial das condicionalidades, por meio da geração de público para acompanhamento, da realização de pesquisas de indivíduos, famílias e extração de relatórios consolidados que orientam a gestão municipal, estadual e federal.

- Visão intersetorial e integrada das condicionalidades, com informações agrupadas por nível municipal, estadual e federal 
As informações dos beneficiários do bolsa família, no que diz respeito às condicionalidades, atualmente se concentram no Sistema de Acompanhamento das condicionalidades (SICON), sob responsabilidade da Secretaria Nacional de Renda de Cidadania (SENARC). Esse sistema é responsável tanto pela geração do público para acompanhamento, ou seja, indica aos ministérios da Saúde e Educação quem deve ser acompanhado pelas condicionalidades, usando informações d- Cadastro Único para Programas Sociais do Governo Federal (CadÚnicoS, bem como pelo recebimento das informações de retorno dos ministériose incorporando-as noNSICON, para, entre outras coisas, aplicar as repercussões nos benefícios.

A ferramenta é um sistema de apoio à gestão intersetorial que integra as informações do acompanhamento de condicionalidades nas áreas de Assistência Social, Saúde e Educação. Permite consultas por parte de instâncias de controle social, como também que gestores e técnicos responsáveis pelo referido acompanhamento nos estados e municípios executem ações, quais sejam, consultar pessoas registradas no Cadastro Único e obter informações de sua família (composição familiar, endereço da família e composição do benefício); consultar famílias com descumprimentos das condicionalidades; registrar e alterar recurso contra os efeitos do descumpriments, quando ocorrerem erros, falhas ou problemas que ocasionem repercussão indevida.

As informações de condicionalidade recebidas peloNSICON tem duas fontes: a primeira é o Sistema de Acompanhamento da Frequência Escolar do Programa Bolsa Família, utilizado pelo MEC, que foi desenvolvido com o objetivo de acompanhar as crianças e adolescentes identificadas no Cadúnico matriculadas nas escolas de todas as regiões do País; A segunde é o programa Bolsa Família da Saúde, que agrega informações sobreeessa área específica. Conceitualmente, o caminho percorrido pelas informações pode ser visto na figura 2 .

5 Guia de Acompanhamento das Condicionalidades do Programa Bolsa Família - Ministério de Desenvolvimento e Combate à Fome - MSD/ 2010.

6 Para uma revisão dos dilemas da Federação Brasileira em programas descentralizados, Cf. Gomes (2009).

7 Para uma revisão da literatura sobre intersetorialidade e seus desafios, cf. Lofrano (2013)

Revista Brasileira de Monitoramento e Avaliação | Número 6 | Julho-Dezembro de 2013 
- FIGURA 1: CICLO DAS INFORMAÇÕES DE CONDICIONALIDADE

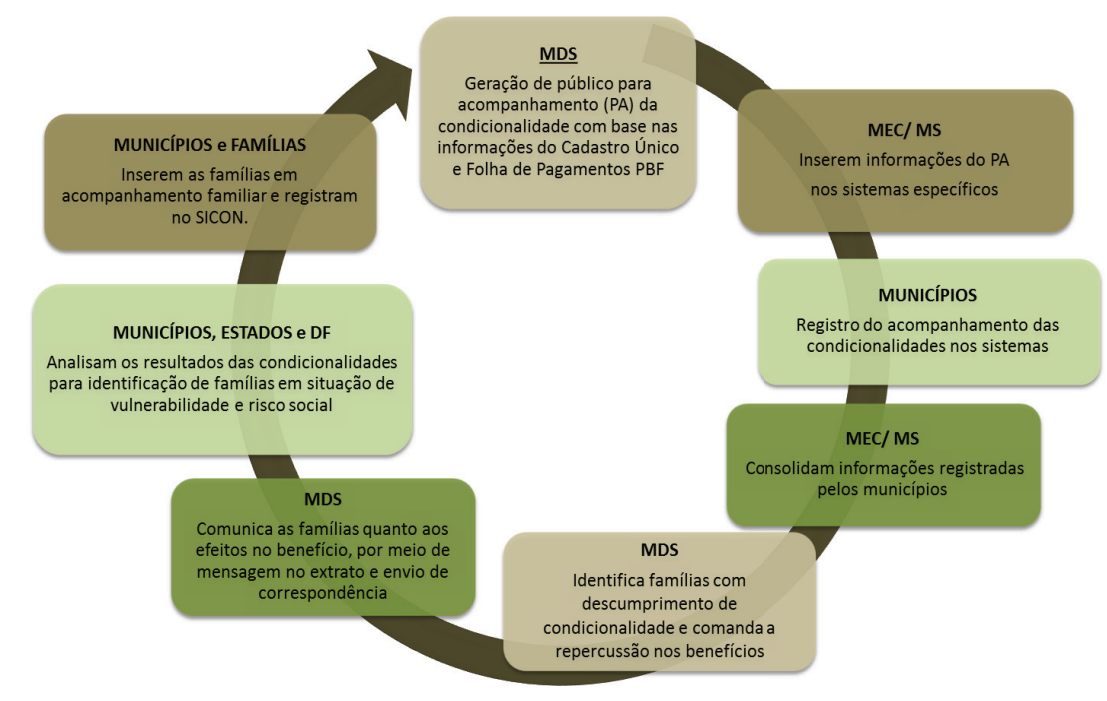

Fonte: Boletim DECON, setembro de 2012

Além disso, três fatores tornam a operação doNSICON ainda mais complexa, sendo o primeiro o fato de os sistemas não serem integrados entre os ministérios, fazendm que a carga dos dados tanto de saída quanto de retorno sejam realizadosapela geração de arquivos e envio para leitura por outros sistemas. O segundo ponto é que oNSICON é uma plataforma de gestão on-line, ou seja, tem de estar funcionando durante todo o tempo. Em terceiro ponto, oNSICON possibilita fazer consultas no nível individual, Essas característicasetornavam extremamente complexa a geração de relatórios que dessem conta das demandas existentes para o monitoramento e acompanhamento do programa. As necessidades de dados paraatais atividades iam muito além disso, havendo demandas por dados agrupados nas seguintes áreas:

- Articulação federativa, especialmente com relação aos estados;

- Elaboração de relatórios sintéticos para o DECON e restante do ministério;

- Elaboração de relatórios analíticos, com séries temporais e divisões territoriais distintas;

- Realização de procedimento que permitissem a construção de padrões de melhores e piores práticas;

- Retorno dos dados para os Estados e municípios, para uso na gestão. 
Embora, em seu modelo de relatórios, oNSICON disponha de catorze indicadores sintéticos, compreendendo toda a série histórica desde o início do programa e todos os níveis geográficos desejados, não era incomum a confecção de tabelas e relatórios utilizando dados consultados diretamente doNSICON, por SOL. Isso fazia que, além de todas as atribuições, essas consultas sobrecarregassem ainda mais o programa. Por isso, foi realizado um trabalho de levantamento de necessidades de informação com todos os indicadores necessários, séries históricas disponíveis e níveis geográficossrequeridos. Em um segundo momento, todos os indicadores e formas de cálculos foram debatidos e validados com os ministérios parceiros, e finalmentesproduziram-se os dados ${ }^{8}$.
Como produto final, foram gerados mais de cem indicadores sistematizados, cujos dados são oriundos de variáveis do Sistema Presença, do Bolsa Família na Saúde e doNSICON. A série histórica dos indicadores inicia-se em 2009, e chega até a última coleta sistematizada, que hoje corresponde a 2013. Com relação à abrangência geográfica, optou-se por deixar, na mesma planilha, os níveis nacional. regional, estadual e municipal. ${ }^{9}$

Conceitualmente, no Painel os indicadores foram organizados e distribuídos em cinco Temas/Dimensões. As dimensões ou "abas" do painel foram separadas pos usos dos dados, então, em alguns casos, os indicadores são duplicados em algumas abas. essas apresentam os seguintes temas:

8 No momento, está sendo feita uma revisão no painel e em seus indicadores, além de realizados alguns teste de consistência e de propriedades dos indicadores. Até agora, a equipe técnica do DECON não encontrou problemas quanto à confiabilidade, cobertura, periodicidade, sensibilidade ou inteligibilidade da maioria dos indicadores, havendo casos isolados que estão sendo tratados. Para uma revisão teórica das propriedades dos indicadores, Cf. Carley (1981) e Jannuzzi (2012).

9 Todo o trabalho inicial de checagem e consolidação dos indicadores foi realizado, por parte do DECON, por dois servidores: Juliana Picoli Agatte e Florentino Chaves Neto. A confecção foi realizada por este último servidor, com o apoio de Luiz Alexandre Paixão. Sem o trabalho abnegado dessas pessoas, especialmente de Florentino, responsável pela concepção técnica e operacionalização em Excel, o painel não existiria.

Revista Brasileira de Monitoramento e Avaliação | Número 6 | Julho-Dezembro de 2013 


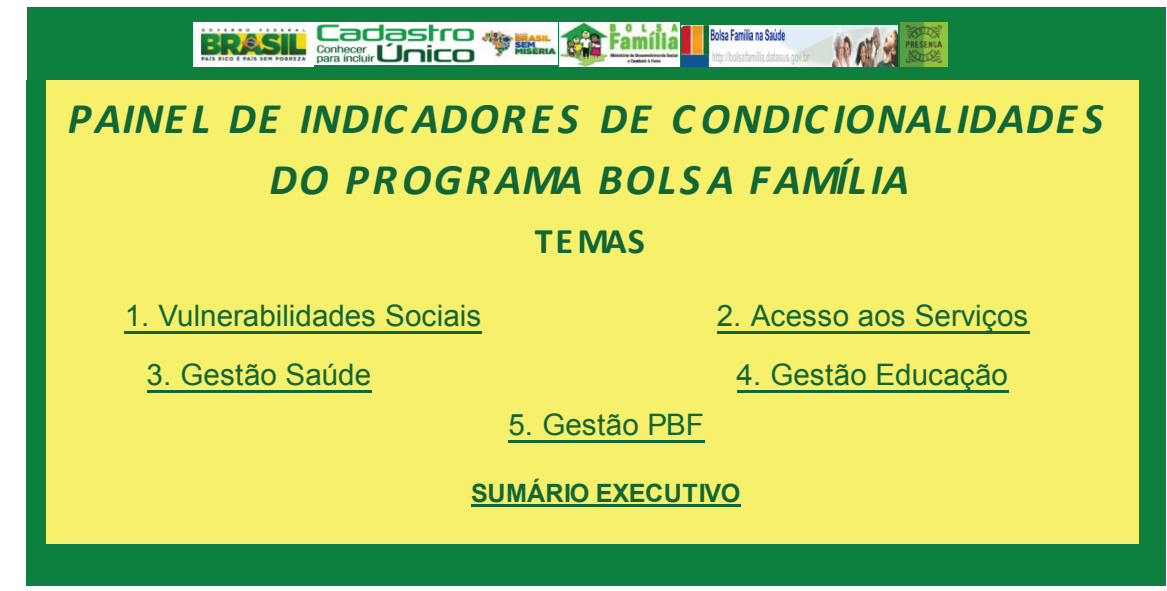

Fonte: Painel de indicadores de condicionalidades (DECON/MDS)

\section{A) INDICADORES DE \\ VULNERABILIDADES SOCIAIS}

As informações são relativas às vulnerabilidades no âmbito das famílias, ou do ambiente em que vivem, as quais possam interferir no acesso aos serviços sociais básicos. Tais informações são apuradas, a partir dos motivos registrados para a baixa frequência escolar no acompanhamento da educação, dos resultados do acompanhamento da saúde, especialmente em relação às informações do acompanhamento do estado nutricional das crianças menores de sete anos, e dos resultados ocasionados pelos efeitos no benefício das famílias, em decorrência do descumprimento de condicionalidades, principalmente suspensão e cancelamento, que podem agravar a situação de vulnerabilidade pela insuficiência de renda mensal.
Estes indicadores podem apontar situações que demandem atuação intersetorial e planejada do poder público, uma vez que é seu dever garantir proteção social às famílias, podendo, ainda, abordar situações recorrentes, relacionadas à saúde, deficiência no crescimento e desenvolvimento das crianças, indícios de abandono escolar, trabalho infantil ou negligência.

\section{B) INDICADORES DE ACESSO AOS SERVIÇOS}

Corresponde às informações do acompanhamento da frequência escolar e da agenda da saúde que podem sinalizar brechas na oferta de serviços públicos, como os educacionais (vagas em escolas, atendimento à pessoa com deficiência, transporte escolar, entre outros) e os de saúde 
(oferta de vacinação, consulta nas unidades de saúde, acompanhamento pelas equipes de saúde da família e pelos agentes comunitários da saúde) no território.

O descumprimento ou o não acompanhamento das condicionalidades podem indicar situações prioritárias a serem enfrentadas pelo poder público, com atuação de perspectiva intersetorial.

\section{C) INDICADORES DE GESTÃO DA SAÚDE}

São indicadores relacionados às ações de gestão da condicionalidade de saúde, sendo estes os percentuais de famílias acompanhadas e não acompanhadas, com especificação daquelas que não foram visitadas e as que não foram encontradas em seus endereços; os resultados do acompanhamento que podem sinalizar situações de insegurança alimentar e nutricional infantil, o percentual de crianças com a caderneta de vacinação desatualizada, bem como informações das gestantes localizadas e acompanhadas pelos municípios.

Estas informações podem revelar tanto lacunas na oferta dos serviços quanto vulnerabilidades de saúde ou oportunidades de aperfeiçoamento do processo de acompanhamento das famílias do PBF.

\section{D) INDICADORES DE GESTÃO DA EDUCAÇÃO}

No indicador de condicionalidade na educação, as famílias do Programa assumem o compromisso de acompanhar e garantir frequência escolar de $85 \%$ da carga horária mensal para crianças e adolescentes entre 6 e 15 anos e de $75 \%$ para adolescentes entre 16 e 17 anos.

Este indicador reúne os percentuais de crianças e adolescentes acompanhados, a frequência acima do mínimo exigido e a baixa frequência, os beneficiários não localizados,saqueles sem informação de frequência pela escola, à falta de informação do motivo da baixaaassiduidada, entre outros. Tais informações permitem identificar possibilidades de aperfeiçoamento do processo de acompanhamento dos alunos beneficiários do PBF.

\section{E) INDICADORES DE GESTÃO DO PBF}

São referentes ao processamento dos dados de acompanhamento das condicionalidades consolidados noNSICON, tais como: o próprio uso doNSICON; o registro do acompanhamento das famílias pelo Sistema Único de Assistência Social (SUAS); a aplicação dos efeitos por descumprimento de condicionalidades (repercussões), iniciada pela advertência, passando pelo bloqueio, suspensão,oaté o cancelamento 
do benefício das famílias; as informações dos recursos apresentados pelas famílias contestando o descumprimento; e o registro de interrupção temporária dos efeitos do descumprimento no benefício das famílias inseridas em acompanhamento familiar.

Apresenta os indicadores relativos às dificuldades encontradas no acompanhamento dos beneficiários por parte dos profissionais de saúde e educação, devido a inconsistências no endereço, que podem refletir problemas relacionados à atualização cadastral de famílias do PBF. Tais informações contribuem para o planejamento de ações e iniciativas intersetoriais direcionadas ao aperfeiçoamento da gestão do Programa e das condicionalidades.

\section{F) SUMÁRIO EXECUTIVO}

O sumário executivo apresenta um apanhado dos principais indicadores na mesma aba, bastando apenasoo código do IBGE do Município para gerar um pequeno relatório, com comparações no nível do Estado e da Região.aDiferencia-se das demais abas por ser analítico e não temático. Também é possível, apenas nessa aba, gerar gráficos de séries históricas diretamente.

\section{EXIBIÇÃO DOS DADOS, SÉRIES TEMPORAIS E DIVISÃO TERRITORIAL}

O principal desafio na construção do paine, foi manter a flexibilidade no uso dos dados, tanto para relatórios pré-configurados quanto para extração dos dados e realização de estudos e notas técnicas. Em verdade, esse dilema não foi resolvido, tendo sido decidido a manutenção do painel em seu formato atual, uma vez que ele se tornou tanto uma ferramenta para obtenção de informações sem tratamento quanto um mecanismo de monitoramento para algumas instâncias do PBF, como veremos na próxima seção. Por isso, além dos procedimentos de PROC-V utilizados para a confecção do painel, foram utilizadas outras ferramentas como subtotais, flags e filtros pré-codificados para possibilitar o tratamento pelo usuário final.

Assim que entra em qualquer das abas temáticas, o usuário depara coa um link para o indicador, com seu número e nome, as variáveis que o criaram, fórmula de cálculo, fonte dos dados, período disponível, a existência e descrição de sinalizadores (flags e escalas). Ao clicar no nome da variável, é levado à aba do indicador selecionado no qual tem acesso à série histórica. 


\section{- FIGURA 4: ÍNDICE DE GESTÃO DA EDUCAÇÃO DO PAINEL DE INDICADORES}

\begin{tabular}{|c|c|c|}
\hline INDICADORES & VARIÁVEIS & FÓRMULA DE CÁLCULO \\
\hline \multirow{3}{*}{ 4.1. Accompanhamento da Frequência Escolar de Criancase e Addolescentes (6 a 15 anos) } & 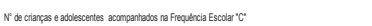 & \multirow{3}{*}{ c/0 } \\
\hline & & \\
\hline & 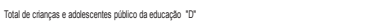 & \\
\hline \multirow{2}{*}{ 4.2- Criancas e Adolescentes Acompanhadoos com Frequência Acima (igual ou superior à 85\%) } & 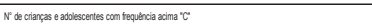 & \multirow{2}{*}{ c/o } \\
\hline & 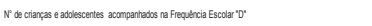 & \\
\hline \multirow{2}{*}{ 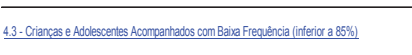 } & 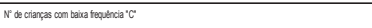 & \multirow{2}{*}{$c / 0$} \\
\hline & 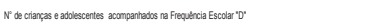 & \\
\hline \multirow{3}{*}{ 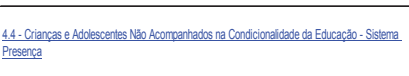 } & 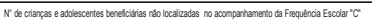 & \multirow{3}{*}{$|(0+D)\rangle$} \\
\hline & 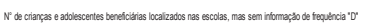 & \\
\hline & 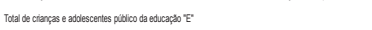 & \\
\hline \multirow{2}{*}{ 4.5. Criancas e Adolescentes Näo Localzados nas Escolas } & 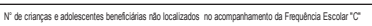 & \multirow{2}{*}{ c/D } \\
\hline & 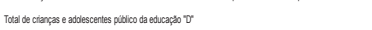 & \\
\hline \multirow{2}{*}{ 4.6- Criancas e Addolescentes Locarizados em escolas, mas sem informacăo de frequência } & 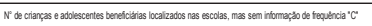 & \multirow{2}{*}{ c/D } \\
\hline & 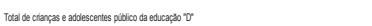 & \\
\hline \multirow{3}{*}{ 4.7-Taxa liquida de informazăo da frequênciia - alunos 6 a 15 anos } & 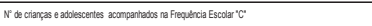 & \multirow{3}{*}{$=C /(D-E)$} \\
\hline & 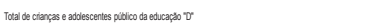 & \\
\hline & 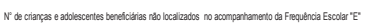 & \\
\hline
\end{tabular}

Fonte: Painel de indicadores de condicionalidades (DECON/MDS)

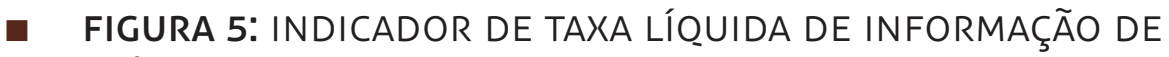
FREQ-UÊNCIA

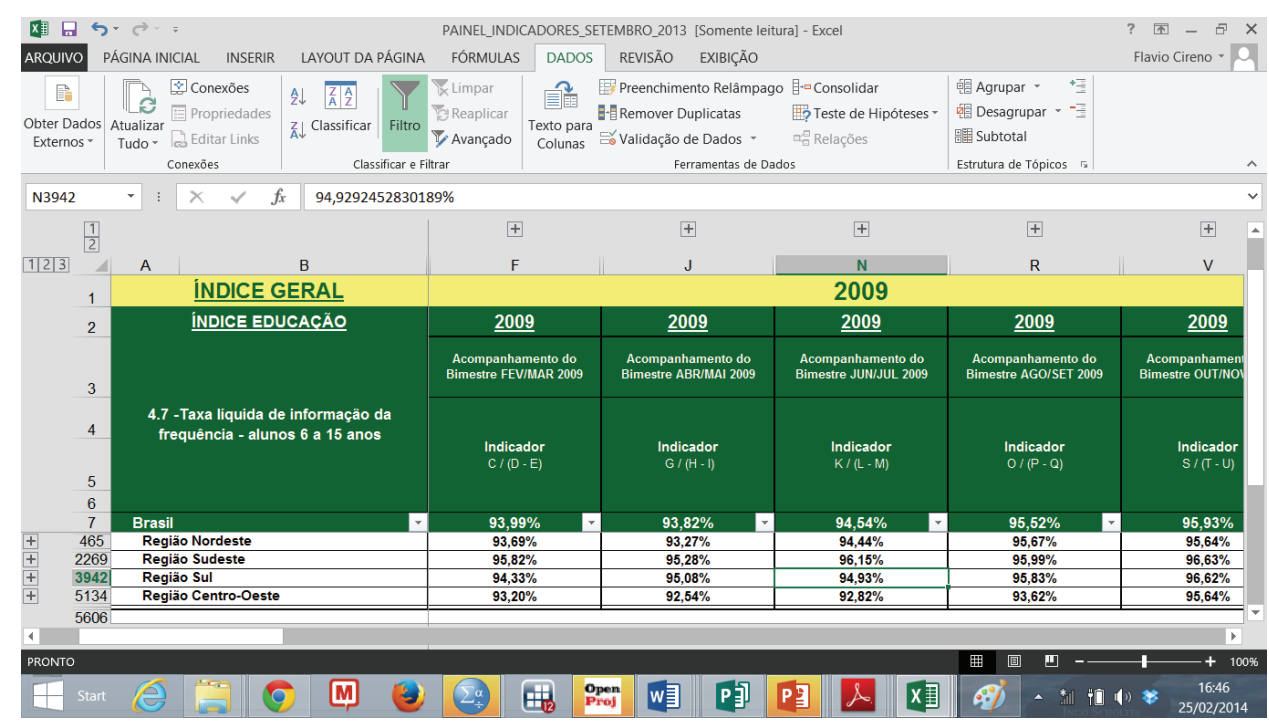

Fonte: Painel de indicadores de condicionalidades (DECON/MDS)

Revista Brasileira de Monitoramento e Avaliação | Número 6 | Julho-Dezembro de 2013 
Além da série histórica para o Brasil e grandes regiões, o usuário tem as opções de expansão das barras de agrupamento e desagrupamento, como mostrado na figura 5. Ao fazer isso, pode ter acesso a diferentes níveis geográficos e aos componentes das fórmulas, isto é, os dados absolutos.

A figura 6 mostra a situação de expansão Unto do nível geográfico quanto da abertura do cálculo do indicador, possibilitando ao usuário o acesso tanto aos indicadores quanto aos números absolutos do cálculo. Esses dados podem ser exportados sem formato algum para outras planiIhas Excel, possibilitando o uso dos dados para a confecção de gráficos e tabelas.
O último recurso introduzido no painel foi o sumário executivo, inserido para facilitar a recuperação de informações de municípios agregadas em uma só tela. Pela ausência de uma ferramenta de $\mathrm{Ti}$ mais sofisticada, foi utilizada novamente a estratégia de PROC-V do Microsoft Excel, em que, ao inserir o código IBGE do município, a tela recupera as últimas informações dos indicadores mais importantes do painel.

Dentro dessa opção, clicando em qualquer dos links sublinhados em azul, neste caso indicados com uma seta azul na figura 7 . leva o usuário a um gráfico de tendência com a série histórica do indicador, como pode ser visto na figura 8.

\section{- FIGURA 6: INDICADOR DE TAXA LíOUIDA DE INFORMAÇÃO DE FREQUÊNCIA}

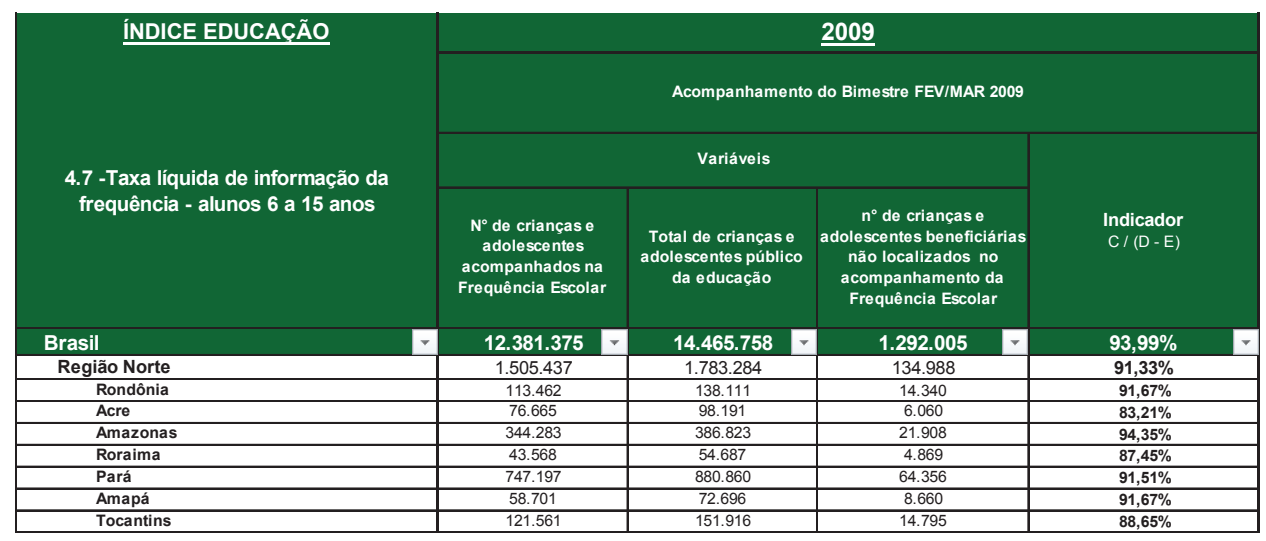

Fonte: Painel de indicadores de condicionalidades (DECON/MDS) 


\section{- FIGURA 7: SUMÁRIO EXECUTIVO DO PAINEL DE INDICADORES DE}

CONDICIONALIDADES PARA A CIDADE DO RECIFE

\begin{tabular}{|c|c|c|c|c|c|}
\hline Gódige IBGE 2611606 & 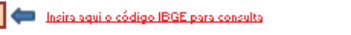 & & & & ÍNDICE. \\
\hline \multicolumn{6}{|c|}{ SUMÁRIO EXECUTIVO DE CONDICIONALIDADES } \\
\hline Temas & Informaçōes & Recife & Pernambuco & Brasil & Ref. \\
\hline \multirow{5}{*}{ Saíde } & \% de Fomíliss Acomponhodos & $42.0 \%$ & 710:0\% & I3.15 & 2'viqEnciado 2012 \\
\hline & N de Famíliso Público pars Acompanhomento & 108.486 & 977.547 & 11.883 .263 & $z^{\prime}$ 'viq6ncia do 2012 \\
\hline & N de Famílise Acompanhadas & 45.518 & 693.314 & 8.689047 & 2 'viqünciade zo12 \\
\hline & N de Crionģas Acompanhadas & 12.488 & 375.372 & 5.175 .023 & 2'viqEncia do 2012 \\
\hline & N'de Gestantes Acomponhadas & 323 & 9.797 & 165.048 & 2 'viqencsia do 2012 \\
\hline \multirow{5}{*}{ Edecaş̌̈o } & \% de Eencficíŕrios 6 a 17 anos Acompanhados & $70.5 \%$ & 82.43 & 84.65 & Abremaio 2013 \\
\hline & N de Beneficírios 6 a 17 anos Público pars Acompanhomento & 133.219 & 1.278 .612 & 17.398 .172 & AbrerMaia 2013 \\
\hline & N' de Eencficí́rios 6 o 17 anoe Acompanhados & 93.857 & 1053.885 & 14.723 .947 & Abremaia 2013 \\
\hline & N de Eenefficíríos 6 o 17 anos com Bsixa Frequêncis & 7.065 & 31.651 & 729.655 & Abremaia 2013 \\
\hline & \&de Eencficí́rios 6 o 17 onos N5́o Localizados & $24,0 \%$ & 15.23 & 12.15 & AbremMaio Z013 \\
\hline & N' de Eenefficíśrios 6 o 17 anos N5o Localizados & 31.950 & 194.519 & 2.105 .388 & AbriMain 2013 \\
\hline & N' de Fomíliss Beneficíśriss do PBF & 131.208 & $\frac{1}{1.135 .143}$ & 13.765 .514 & Aquertatzo13 \\
\hline \multirow{9}{*}{ Gest5o PBF } & N de Fomíliss com Acomponhomento dos Condicionslidades & 55.654 & 563.508 & 7.759 .776 & Repore.Julhatz2013 \\
\hline & N' de Fomílias que Descumprirom as Condicionalidades & 2.897 & 15.350 & 310.152 & Repore. Julhatz2013 \\
\hline & N de Fomílios com $r$ Suepenesó & 589 & 2.430 & 59.253 & Ropere. Maurzo12 \\
\hline & N' de Fomílise com 2 ' Suspeneso & 297 & 1.163 & 31830 & Ropore. Nautz2012 \\
\hline & N de Fomílios em Suspeneso & 418 & 1.184 & 40.457 & ReporeseJulhatz2013 \\
\hline & N' de Famílias Cancelodos & a & 0 & Q & Repore, Julthat2013 \\
\hline & Nede Fomílise em Acompanhomento Fomilisr & a & Q & 2 & 317ivilhatzo13 \\
\hline & N' de Famíliso com Interrup śo Temporáris & 0 & 0 & 0 & 30tabrillz2013 \\
\hline & N'de Recurses On-line Cadastrodos & 196 & 1.485 & 27.552 & Repore.Maiat2013 \\
\hline & N' de Recursos On-line Deferidos & 176 & 1.371 & 23.667 & Riepers.Maiot2013 \\
\hline
\end{tabular}

Fonte: Painel de indicadores de condicionalidades (DECON/MDS)

- FIGURA 8: SUMÁRIO EXECUTIVO dO PAINEL DE INDICADORES DE CONDICIONALIDADES PARA A CIDADE DO RECIFE

INDICE GERAL

Brasil SUMÁRIO EXECUTIVO

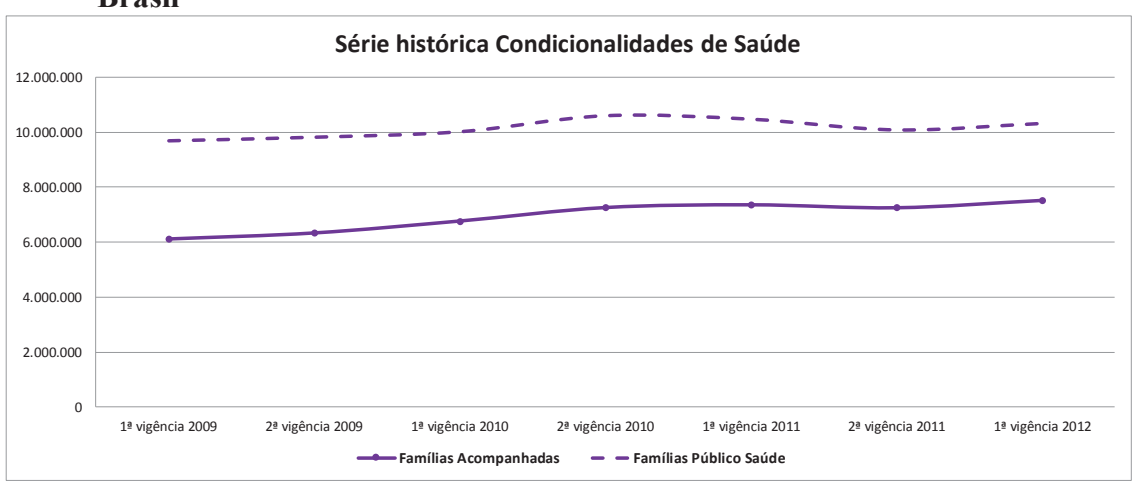

Fonte: Painel de indicadores de condicionalidades (DECON/MDS)

Revista Brasileira de Monitoramento e Avaliação | Número 6 | Julho-Dezembro de 2013 


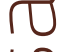

Dessa forma, embora com recursos limitados, procurou-se atender as demandas existentes por informações de condicionalidades no âmbito do MDS, dos estados e municípios.

U

(1)

(1)

$\checkmark$

Un

0

$+$

\section{USOS NA GESTÃO E OS PRODUTOS DERIVADOS DAS INFORMAÇÕES EXISTENTES.}

O painel de indicadores, desde que foi lançado em 2012, foi utilizado em vários estudos e relatórios do próprio MDS, compreendendo três Secretarias Nacionais e o próprio Gabinete da Ministra. A SAGI, Secretaria Nacional de Avalição e Gestão da Informação, a SENARC, Secretaria Nacional de Renda de Cidadania, responsável pela operação do Programa Bolsa Família e a SESEP - Secretaria Extraordinária para a Superação da Extrema Pobreza, responsável pelo Plano Brasil sem Miséria, utilizam corriqueiramente as informações do Painel. Além disso, o painel foi utilizado várias vezes para a confecção de apresentações e relatórios especiais para o Gabinete da Ministrl. Fora Isso, os dados do painel tem sido usados para o planejamento de ações federativas tanto da SENARC, como também dos Estados membros por meio de suas comissões intersetoriais. Em complemento, os dadososervem de subsídio para a SFGI, alimentando o MONIB - Monitoramento do BrasilsSem Miséria. Os dados do Painel de indicadores de condicionalidades tem sido usados para os seguintes fins:

- Monitoramento dos indicadores de:

- Vulnerabilidade;

- Gestão do programa;

- Oferta de serviços;

- Apresentações de resultados;

- Relatórios;

- Alimentação de sistemas;

- Planejamento no nível federal e estadual;

- Boletins e publicações do MDS

Finalizando, o papel do Painel de indicadores superou a ideia inicial de organização e sistematização de dados de monitoramento das condicionalidades do Programa Bolsa Família, sendo hoje central para uma série de atividades do DECON, da SENARC e de suas relações com outras secretarias do Ministério do Desenvolvimento Social e Combate à fome, além do Gabinete da Ministra. Em complemento, a disponibilização e circulação das informações sobre condicionalidade trouxeram uma maior visibilidade e ajudaram a melhorar o planejamento no nível nacional e subnacional. 


\section{Referências bibliográficas}

CARLEY, M. Indicadores sociais: teoria e prática. Rio de Janeiro: Zahar, 1981.

GOMES, S. Políticas Nacionais e Implementação Subnacional: Uma Revisão da Descentralização Pós-Fundef. DADOS - Revista de Ciências Sociais, Rio de Janeiro, l. 52, no 3, pp. 659 a 690, 2009

JANNUZZI, P. de $M$, Indicadores Sociais no Brasil: conceitos, fontes de dados e aplicações. 5.ed. Campinas, SP: Editora Alínea, 201..
SANTOS, R. L. A. dos. Governança e coordenação em arranjos multinível de políticas públicas transversais: assistência social, educação e saúde no Programa Bolsa Família. 2013. 171f. Dissertação (mestrado) Escola Brasileira de Administração Pública e de Empresas - Fundação Getúlio Vargas, Rio de Janeiro, 2013. 